\title{
Performance of Trim Coils Made by a Novel Method
}

\author{
P.Wanderer, M.Anerella, J.Cottingham, G.Ganetis, M.Garber, A.Ghosh, C.Goodzeit", \\ A.Greene, R.Gupta, J.Herrera, S.Kahn, E.Kelly, A.Meade, G.Morgan, J.Muratore, \\ A.Prodell, M.Rehak, E.P.Rohrer, W.Sampson, R.Shutt, J. Skaritka*, P.Thompson, and \\ E.Willen \\ Brookhaven National Laboratory, Upton, New York 11973 USA

\section{QUENCH TEST RESULTS}

\begin{abstract}
A precision, automated method of manufacturing trim coils based on printed circuit technology has been developed. Excellent quench performance and increased radiation resistance have been achieved in recently-tested models of sextupole trim coils developed for operation inside $\mathbf{4 0} \mathrm{mm}$-aperture SSC Main Collider dipoles.
\end{abstract}

\section{INTRODUCTION}

In the Conceptual Design Report for the Superconducting Super Collider (SSC), certain corrections were to be made "locally" by superconducting trim coils located inside the main collider dipoles ${ }^{[1]}$. To achieve this goal, printed circuit technology for precisely placing wires was adapted to the manufacture of trim coils. An initial test of this method gave encouraging results ${ }^{[2]}$. Following this initial test, development continued in order to improve the quench performance and radiation hardness of the system. In this paper, test results from two short models and one full-length model are reported.

\section{TRM COIL CONSTRUCTION}

Three trim coils were tested. Two were short test models $1.3 \mathrm{~m}$ long, tested in $1.8 \mathrm{~m}$-long dipoles. One was a fulllength model $(10 \mathrm{~m})$, tested in a full-length $(17 \mathrm{~m})$ dipole. All three trims were wound with 20 turns of multifilamentary wire. The wire used in the short trims was $0.35 \mathrm{~mm}$ in diameter; in the long trim the diameter was $0.325 \mathrm{~mm}$.

The wire was located to an accuracy of about $25 \mu \mathrm{m}$ by pushing it into a flat, pliable substrate. The substrate was epoxy-bonded to the $34.544 \mathrm{~mm}$ O.D. cold bore tube, which had previously been wrapped with Kapton ${ }^{[3]}$ insulating tape and fitted with locating pins. A wet layup of epoxy-impregnated fiberglass tape was then placed over the substrate. The cured epoxy provided support against radially-outward and tangential wire motion. Details of the initial construction methods have been previously published ${ }^{[4]}$; the present method will be described elsewhere.

\footnotetext{
Work supported by the U.S. Department of Energy.
}

The most severe test of the trim coil occurs when the central field of the dipole is maximum, 6.6 T. The required current in the trim at this dipole field is about 15-20 A. One trim coil did not train in either polarity, with plateau quench currents of $47 \mathrm{~A}$ independent of polarity. This was in agreement with the short-sample estimate of $45 \mathrm{~A}$. The polarity was reversed several times, and no training was found.

The other trim coil quenched initially at $18 \mathrm{~A}$ and trained to over $40 \mathrm{~A}$ in 11 additional quenches. Due to test difficulties, additional quenching was at a slightly lower field (6.1 T), where it wis found that the trim did not require added training when powered with the opposite polarity. Also, no further training was found when the polarity was reversed several times. For both trims, the plateau quench currents increased to $107 \mathrm{~A}$ at $2.5 \mathrm{~T}$ dipole field ${ }^{(s)}$.

During the R\&D program, the trim coil length was reduced from $17 \mathrm{~m}$ to $10 \mathrm{~m}$ with the same integral field requirement. The increased performance demand was met by increasing the number of turns from 17 to 20 and by increasing the wire size. Roughly speaking, the Lorentz force per turn was about $50 \%$ higher than originally. Nonetheless, the quench performance at $6.6 \mathrm{~T}$ (as judged by the margin over operational current) was significantly better than that achieved in the original trim coil program.

\section{MAGNETIC FIELD MEASUREMENTS}

In discussing the multipole fields of the trim coil, we consider the results normalized to a background dipole field of $2 \mathrm{~T}$. The notation for the multipole representation of the magnetic field is defined by the following equation:

$$
B_{y}+i B_{x}=B_{0} \sum_{n=0}^{\infty}\left(b_{n}+i a_{n}\right)(x+i y)^{n}
$$

where $B_{0}$ is the dipole field and $x$ and $y$ are the horizontal and vertical coordinates measured from the magnet center. It is convenient to define a multipole "unit" as $10^{-4}$ of the dipole field, with the multipoles evaluated at a radius of 1 
$\mathrm{cm}$. In this notation the normal sextupole is $b_{2}$.

The trim coil correction to the dipole field is largest as a fraction of the dipole field at injection, where the $b_{2}$ correction is 3.5 units. (Actually, the $10 \mathrm{~m}$ trim produces six units of $b_{2}$ locally, to correct the magnetization of the $17 \mathrm{~m}$ trim.) In order to easily compare the trim coil fields to the SSC tolerances on magnetic field harmonics, the trim coils are treated as though they had the same length as the dipole in the following discussion. The SSC tolerances used here are scaled from the tolerances of the $50 \mathrm{~mm}$-aperture dipoles.

There is some interaction between the magnetization currents in the dipole and trim coil. To establish repeatability, the following procedure was followed: First, the dipole was cycled to high field, very low field, and then up to the desired level (e.g., 2 T, 6.6 T). Next, the trim was cycled twice through its bipolar operating range. Measurements taken following this procedure were reproducible at the level of the measuring coil short-term repeatability (typically, a few hundredths of a unit in sextupole, for example).

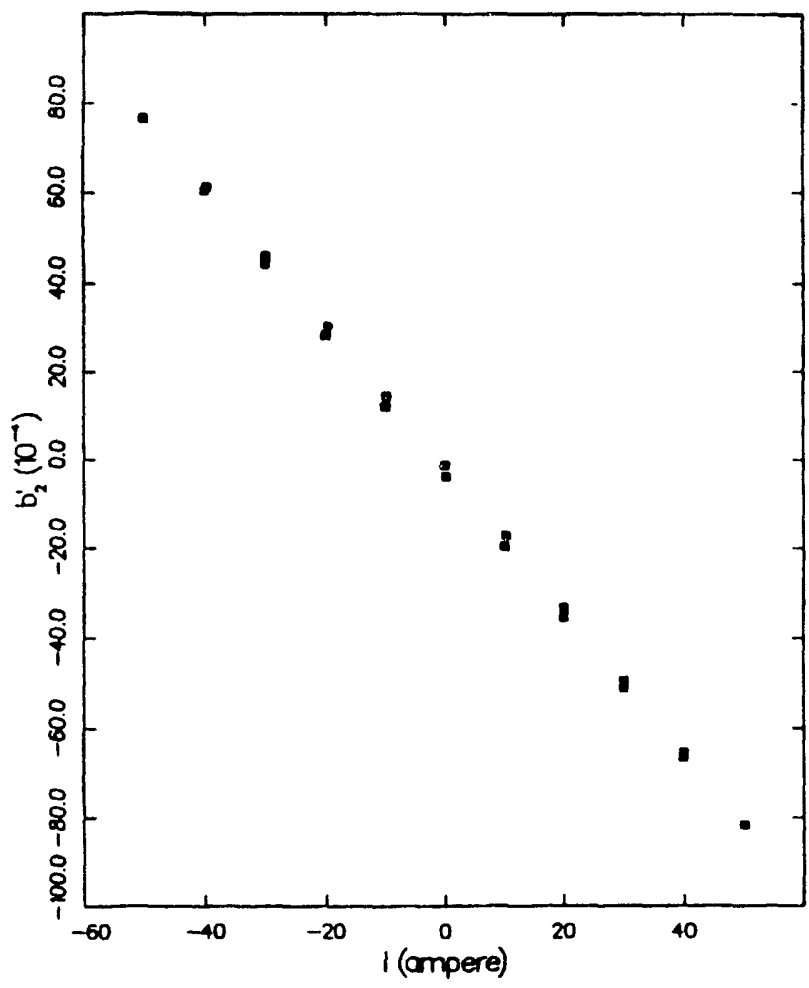

Figure 1. Measured sextupole field coefficient vs. trim coil current for two $1.3 \mathrm{~m}$ trim coils in $2 \mathrm{~T}$ background dipole fields.

The trim coils $\quad-\quad$ a field of $3.4 \times 10^{-4} \mathrm{~T} / \mathrm{A}$ at a radius of $1 \mathrm{~cm}$. The two-dimensional field strength of the three coils varied $3 \%$. The linearity of the field strength with trim coil current can be seen in Figs. 1 and 2. In Fig. 1, in a background dipole field of $2.5 \mathrm{~T}$, a small amount of magnetization can be seen as a difference in the sextupoles measured with increasing trim current and decreasing trim current. The data for the two $1.3 \mathrm{~m}$ trims are both plotted; differences between the two are too small to see in this plot. Fig. 2 shows the trim coil measurements made in a background field near the SSC operating field.

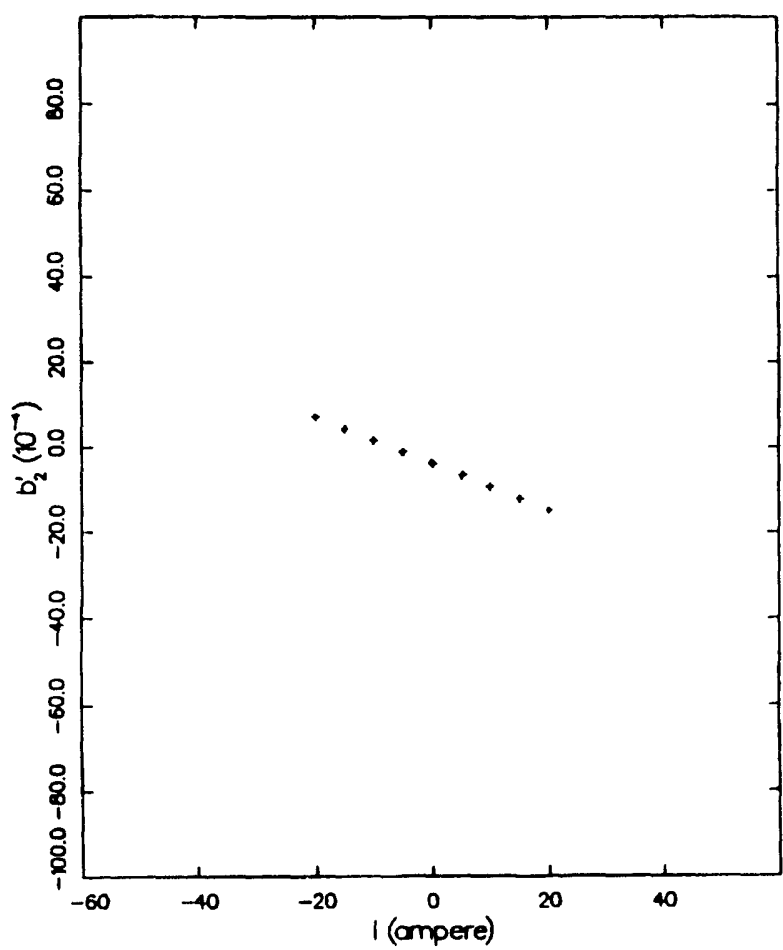

Figure 2. Measured sextupole field coefficient vs. trim coil current for a $1.3 \mathrm{~m}$ trim coil in $\& 6.1 \mathrm{~T}$ background dipole field.

For the $10 \mathrm{~m}$ trim coil, the angle between the dipole field and the trim coil field had an average value of 1.4 degrees, with an rms variation of 0.5 degrees. For the two $1.3 \mathrm{~m}$ trim coils, the values of this angle were -1.3 degrees and 0.3 degrees.

The angular misalignment produces a skew sextupole (a). For the $10 \mathrm{~m}$ trim, the average skew sextupole is about $10 \%$ of the normal sextupole, or about 0.3 units at injection. If this misalignment were random (the most likely case), it would be acceptable, since it is half the tolerance for the rms variation in $a_{2}, 0.6$ units, and would be added in quadrature to the errors in the dipole itself. If it were systematic, it would have to be reduced significantly to be a small fraction of the systematic tolerance, 0.05 units.

The relative transverse locations of the dipole and trim coil were determined by taking the difference between the offcentering of the two magnets with respect to the rotating coil. The 20-pole terms were used in the dipole offcentering calculation, and the quadrupole terms in the trim 
coil analysis. The difference between the centers of the dipole and the trim was about $0.2 \mathrm{~mm}$ in both $x$ and $y$. The consequence of this is that the beam in the center of the dipole sees an apparent quadrupole term. If the offset, $0.2 \mathrm{~mm}$, is random (again, the most likely case), the resulting quadrupole terms, 0.14 units, would be much less than the tolerances for the rms variation (1.74 units for $a_{1}, 0.70$ units for $b_{1}$ ). A systematic offset of $0.2 \mathrm{~mm}$ would be unacceptably large, since the systematic tolerance for the quadrupole terms is 0.05 units.

The multipoles higher than the sextupole are small as a fraction of the trim coil field. The largest is the octupole $(0.5 \%$ to $2.5 \%$, at $1 \mathrm{~cm}$ radius), followed by the decapole $(0.3 \%$ to $0.6 \%)$. The remaining terms are $0.2 \%$ or less. The first allowed term $\left(b_{8}\right)$ is $0.04 \%$.

Comparison of the octupole to the tolerances gives the following conclusions: the normal octupole $b_{3}(0.03$ to 0.08 units) is acceptable if the error is random (tolerance 0.35 units) but marginal if it is systematic (tolerance 0.05 units). The skew octupole terms are half the normal octupole terms, and acceptable either as random or systematic errors. In the analysis of the previous series of trim coils, it was concluded that the most likely source of the octupole was a gap between the edges of the substrate wrapped around the cold bore tube. This would be the focus of effects if the octupole terms were systematically too large.

In the previous trims, made with monofilament conductor, it was found that the decapole term due to magnetization effects was significani. Multifilamentary conductor was used in the three trims reported here, and magnetization-induced decapole terms were negligible. In the first of the three trim coils of this set, the geometric decapole was too large, but it was negligible in the next two coils.

\section{v. CONCLUSIONS}

Quench test and field measurements from this set of three trim coils were substantially better than for the initial set of trim coils. Insofar as can be determined from three coils, the trims met the required specifications. The use of these coils was made unnecessary in the current SSC design (SSC SiteSpecific Conceptual Design Report), and this note marks the conclusion of this effort.

However, trim coils made with this construction method will be used in the Relativistic Heavy Ion Collider (RHIC), now under construction at BNL. The four-layer corrector will contain dipole, quadrupole, octupole, and decapole windings ${ }^{[6]}$. In RHIC, the trim package occupies its own slot in the lattice, thus removing the requirement of operation in a large background dipole field. Tests of the initial RHIC trims have also been quite encouraging.

\section{REFERENCES}

- Now at Superconducting Super Collider Laboratory, 2550 Beckleymeade Ave., Dallas, TX 75237, USA

[1] "Conceptual Design of the Superconducting Super Collider, " SSC-SR2020, SSC Central Design Group, Lawrence Berkeley Laboratory, One Cyclotron Rd., Berkeley, CA 94720 (March 1986).

[2] "Performance of R\&D Sextupole Trim Coil for SSC Dipoles," P.Wanderer, J.Herrera, P.Thompson, and E.Willen, Proc. 1987 IEEE Part. Accel. Conf., Washington, DC, March 16-19, 1987, p.1472 (IEEE, Piscataway, NJ).

[3] Kapton is a registered trademark of the DuPont Corp.

[4] "Development of the SSC Trim Coil Beam Tube Assembly," J.Skaritka, E.Kelly, W.Schneider, R.Shut,, P.Thompson, P.Wanderer, E.Willen, D.Bintinger, R.Coluccio, and L.Schieber, Proc. 1987 IEEE Part. Accel. Conf. Washington, DC, March 16-19, 1987, p. 1437 (IEEE, Piscataway, NY).

[5] The $10 \mathrm{~m}$ trim was not quenched due to limitations on the testing of the dipole in which it was mounted.

[6] G.Morgan, F.Short, J.Skaritka, and P.Thompson, "Geometry of an All-Multiwire RHIC Corrector," Brookhaven National Laboratory Magnet Division Note 256-16 (RHIC-MD-68) 1988 (unpublished).

\section{DISCLAIMER}

\footnotetext{
This report was prepared as an account of work spensored by an agency of the United States Government. Neither the United States Government nor any agency thereof, nor any of their employees, makes any warranty, express or implied, or assumes any legal liability or responsibility for the accuracy, completeness, or usefulness of any information, apparatus, product, or process disclosed, or represents that its use would not infringe privately owned rights. Reference herein to any specific commercial product, process, or service by trade name, trademark, manufacturer, or otherwise does not necessarily constitute or imply its endorsement, recommendation, or favoring by the United States Government or any agency thereof. The views and opinions of authors expressed herein do not necessarily state or reflect those of the United States Government or any agency thereof.
} 

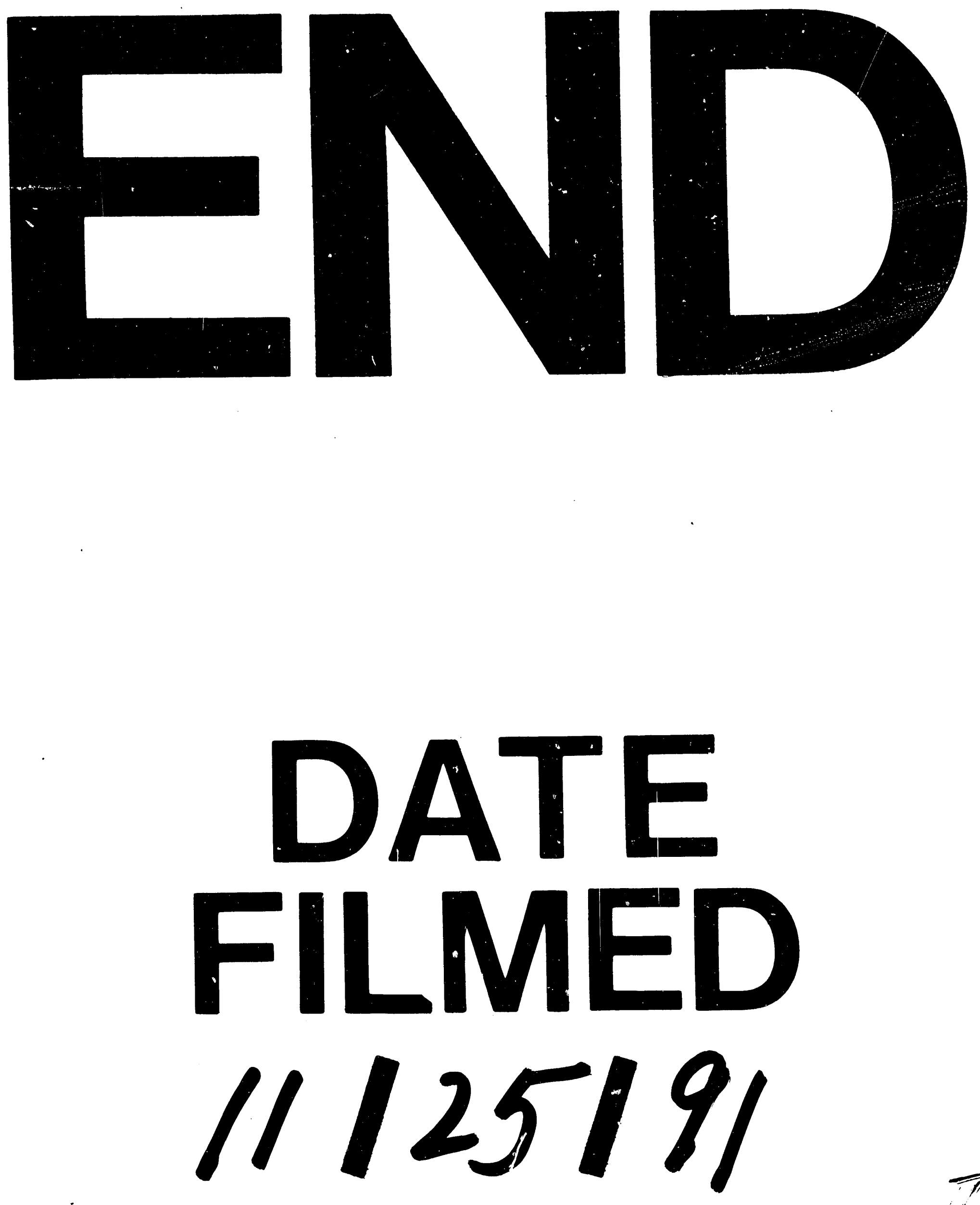

$\overline{11}$ 
